\title{
¿Qué aspecto debe tener una iglesia?
}

Si nos referimos a edificios destinados a la celebración del culto religioso, ¿podemos hablar de la existencia de un denominador común?... Creo que sí; más aún, espero que la cuestión planteada desde este punto de vista presente una respuesta fácil y susceptible de utilización práctica. Pero hoy quiero hablar únicamente del aspecto y de las impresiones visuales que una iglesia debe ofrecer.

Nuestro actual conocimiento del hombre-es decir, del maravilloso rey de la creación que toma carne individual en las formas más dispares-se acerca mucho más a la auténtica envoltura de su alma, de lo que se acercaba el concepto mecanístico, ya muerto y enterrado, del siglo XIX. Aún quedan explicaciones asombrosamente ingenuas entre un cerebro y el último modelo electrónico; pero todos los psicólogos verdaderamente informados, se alejan más y más de estas explicaciones basadas en esquemas mecánicos y rígidos.

Eil materialismo f̂ué la úitima novedad hace cien años, cuando Buchehner escrioió sū famoso libro "Fuerza y materia". Pero hoy en día, la materia es un enigma silencioso que nada explica; ella misma, en su origen y esencia requiere demasiada explicación.

Yo soy un arquitecto que hace planos, y sé que mis planos deben amoldarse a un plano mayor. Lo que proyectamos y colocamos en un paisaje, debe estar absorbido por él y debe ser orgánicamente tolerable. Y este paisaje se extiende desde distancias solemnes, universales y telúricas, hasta las más mínimas sensaciones de nuestras facultades "teleceptivas", hasta los dedos invisibles de nuestra piel, y, desde ella, hasta el desconocido cerco de nuestra vitalidad interior, percibida por medio de sentidos "propioceptivos" y "enteroceptivos".

El arquitecto del futuro se ocupará-modesto y lleno de adoración-en alojar conjuntamente el cuerpo y el alma humana, y servirá con toda fidelidad sus actividades y sus reflejos. Venerará la creación con más vigor que sus antepasados, y rendirá debido culto a la divinidad y a las misteriosas fuerzas que alientan detrás de la vida aparente. "Elohim", la palabra que emplea la Biblia para designar la Divinidad, es un plural; sin embargo, con ella comienza el monoteísmo, que proclama al hombre, imagen de su Dios. Esto es, más que una contradicción, un profundo conocimiento de la realidad.

En el pasado, el ateísmo podía ser sofisticado. En el futuro aparecerá como rebelión infantil y áspera contra algo que el hombre nunca ha podido-y casi nunca ha querido-evitar, en los miles de años que nuestros historiadores registran.

Yo mismo me he esforzado en expresar con claridad mis pensamientos y mis sentimientos a través de charlas y publicaciones, y he tratado de explicar los elementos primarios de la acción de adorar, que origina, a su vez, una larga serie de ceremonias. El arquitecto, con mayor razón que otras personas, debe respetar estas creencias maravillosas.

El arquitecto debe fomentar las expresiones externas que nuestro cuerpo, naturalmente, necesita. Además, debe comprender la postura de una persona que reza; postura que entraña un glorioso ascenso a las alturas y un modesto descenso a nuestra pobre carne mortal.

Este género de cosas no puede percibirse por medio de cinco inexpresivos sentidos. El hombre, tal como ahora le conocemos, tiene millones de pequeños centros nerviosos perceptores, que perciben la complejidad fabulosa de su medio ambiente. Todos hemos notado con asombro que la visión periférica de nuestros ojos percibe toda la amplitud 
del interior de una iglesia, para terminar fijándose en un punto determinado y sobresaliente de su conjunto. Nuestro cerebro recibe en primer lugar las impresiones de la nave de una catedral, en toda su amplitud; el conjunto de esta visión, estimula nuestra actividad y nos obliga a caminar despacio, en dirección al altar. Escuchamos la resonancia de nuestros pasos, sentimos nuestro penetrante calor en la atmósfera húmeda, aspiramos la sabiduría en forma de olor de las velas o de las viejas losas, o bien notamos la diferencia entre el aire usado y el puro que sigue su curso natural. Es sólo un ejemplo, y ya hemos empleado una multitud de sentidos. No existe sólo la vista, sino mucho más. Todas nuestras percepciones simultáneas-e incluso algunas de las que no lo son-se funden en un haz "stereognóstico" según la terminología de la más moderna psicología. La vista no es un departamento separado, que empleamos a discreción mientras paseamos por este gran establecimiento humano que es también indivisible. Todas nuestras facultades sensoriales están relacionadas intimamente con la zona central e interior donde se almacenan nuestros recuerdos plásticos y nuestras tradiciones, cada una con su peculiar aspecto emocional.

El proyectista de iglesias no puede ser sólo un racionalista o un buen técnico. Tiene que amar y respetar a los hombres, a las mujeres y a los niños, a las maravillosas criaturas que componen nuestra humana congregación. Estas criaturas, a diferencia de los pájaros, de las abejas y de los osos, se renuevan y reaccionan profunda y conscientemente. En la tradición judaicocristiana, la palabra es lo primero, y, pronunciada en alta voz o dicha en silencio, constituye el centro de las funciones de una iglesia. $Y$ la palabra necesita una casa construída con amor hacia la especie humana, que es, a su vez, donación maravillosa de Dios.

\section{Capilla Miramar - La Jolla - California}

Las catedrales, las iglesias y las capillas suelen proyectarse en sitios destacados y con siluetas elevadas y esbeltas. Esta capilla Miramar pertenece a los pilotos de la armada norteamericana, los cuales, antes de partir hacia misiones peligrosas e inciertas, vuelan en círculo sobre la base. Desde arriba lanzan una mirada postrera a la única edificación espiritualmente acentuada, que ocupa el centro de un complejo militar repleto de detalles técnicos. La capilla, su verde y enclaustrado patio, la línea de clases y el pequeño concilio, forman un conjunto inolvidable, fácil de retener en la memoria. La sombra que arroja el grupo sobre el suelo produce una impresión renovada y distinta, según la estación del año o la hora del día.

Los arquitectos han comprendido que las religiones occidentales tienen en común la necesidad de expresar un dinámico y procesional "movimiento hacia..." el altar o foco del culto.

El espacio es la gran experiencia universal del hombre, y tiene para el mismo una pesada carga de sentimiento religioso. Pero este espacio no es el espacio geométrico, racional abstractamente analizado por Euclides, sino un espacio experimentado a través de nuestros millones de sentidos y toda nuestra esencia interior. En contraposición con el diferente espacio euclidiano, la vibrante y memorial experiencia de aquél es "direccional". Tiene "altos y bajos", un "más allá" y "algo oculto"..

La naturaleza nos ha puesto los ojos en la parte frontal de la cabeza y no es mero accidente que nuestros brazos y nuestras piernas nos lleven hacia donde la mirada conduce. Todo nuestro sistema nervioso marca con énfasis "una dirección" en este espacio que ha adquirido acento espiritual a través de miles de centurias y desde Luxor a Chartres.

Además del natural movimiento horizontal, ha de ser expresada también una tendencia ascensional hacia el cielo, que sea, por necesidad, más visual. Este sentimiento debe impresionar al visitante en el momento de entrar a la iglesia y, mejor todavia, ha de entreverlo ya aún antes de entrar.

En la capilla de Miramar se crea este sentimiento, y de un modo tal, que se grava indeleblemente en la memoria del observador. Empezando por el exterior, vemos una campana simbólica, como instrumento tradicional utilizado para convocar y reunir a los fieles. Esta campana se haya siluetada en un hueco translúcido y abierto que se ilumina por la noche, cuyo hueco se ve sobre el ángulo formado por una gran $\gamma$-forma expresiva-que corresponde a la línea adoptada por la cubierta en el interior. Desde el extremo de esta gran V cuelga una escalera única, que acentúa el simbolismo espiritual ascendente. Una simple pantalla de cristal separa el interior del exterior, en esta zona, de modo que, con la elevación de la entrada, ésta invita a entrar.

La entrada a la nave principal se hace a través de un arco, bajo el balcón, en el interior de un porche-vestíbulo muy interesante, desde el cual puede uno ascender por la escalera hasta la galería, o entrar directamente en la iglesia. 


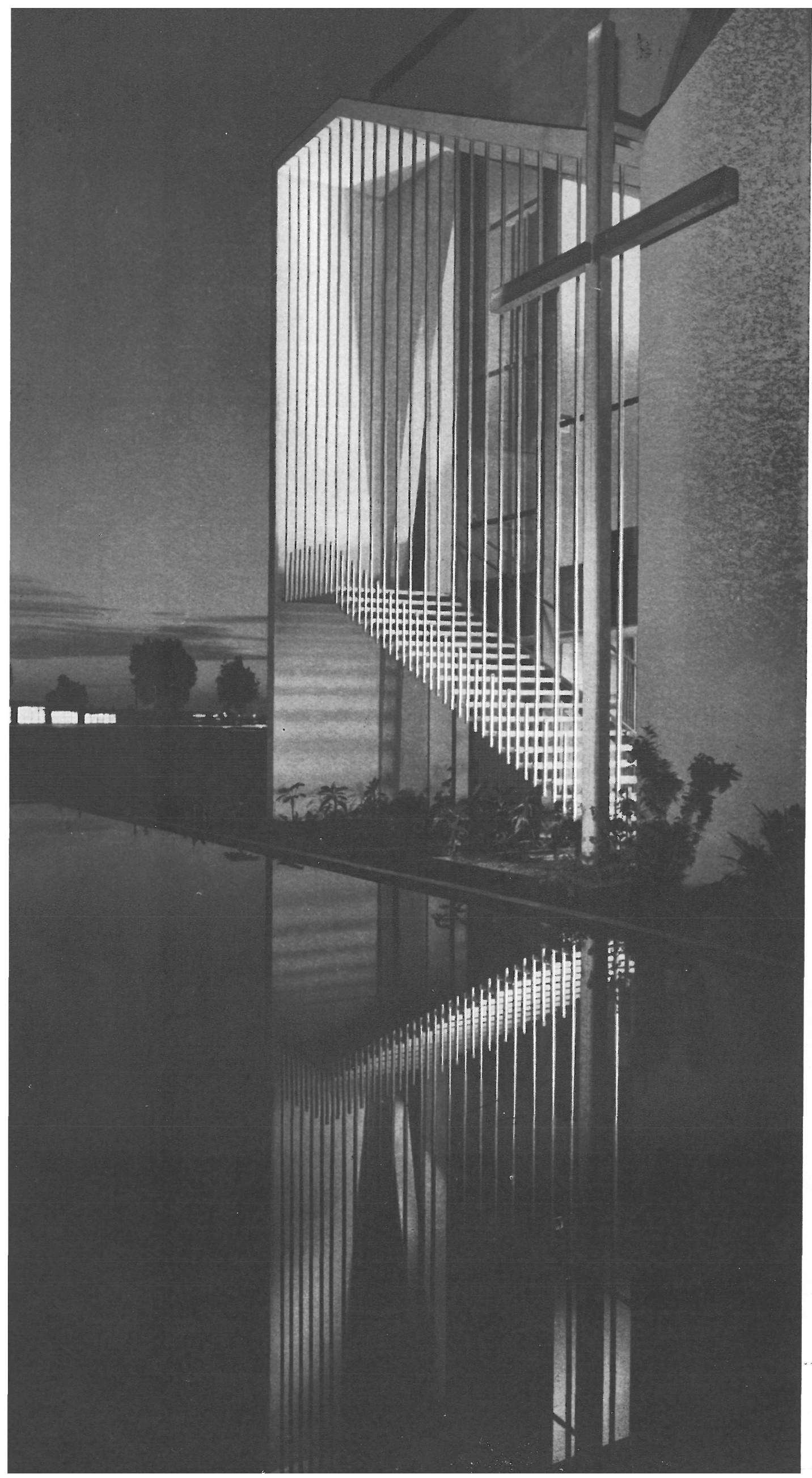

Inmediatamente después de entrar uno experimenta la sensación de surgir entre los macizos que constituyen los pilares de los pórticos, que distribuídos a ambos lados, desaparecen en lo alto, tras el techo como sobre las nubes. La única luz natural, aunque tamizada, accede entre estos macizos, de modo que, oculta, derrama su iluminación hacia el altar y no hacia el observador. La misma forma de techo suspendido, más alto en los bordes que en el centro, parece elevarse, a la vez que el sentido ascendente de la quilla, desde la entrada al ábside, guía la mirada hacia el altar.

El altar está igualments iluminado de forma tenue e indirecta por una cristalera que cruza toda la anchura de la nave, bajando un poco por los lados del presbiterio o de la plataforma del púlpito.

Una desusada y dinámica división graduada del muro posterior del altar, eleva el efecto de perspectiva y refuerza la importancia espiritual del altar hacia el cual converge todo el direccionalismo del programa. 


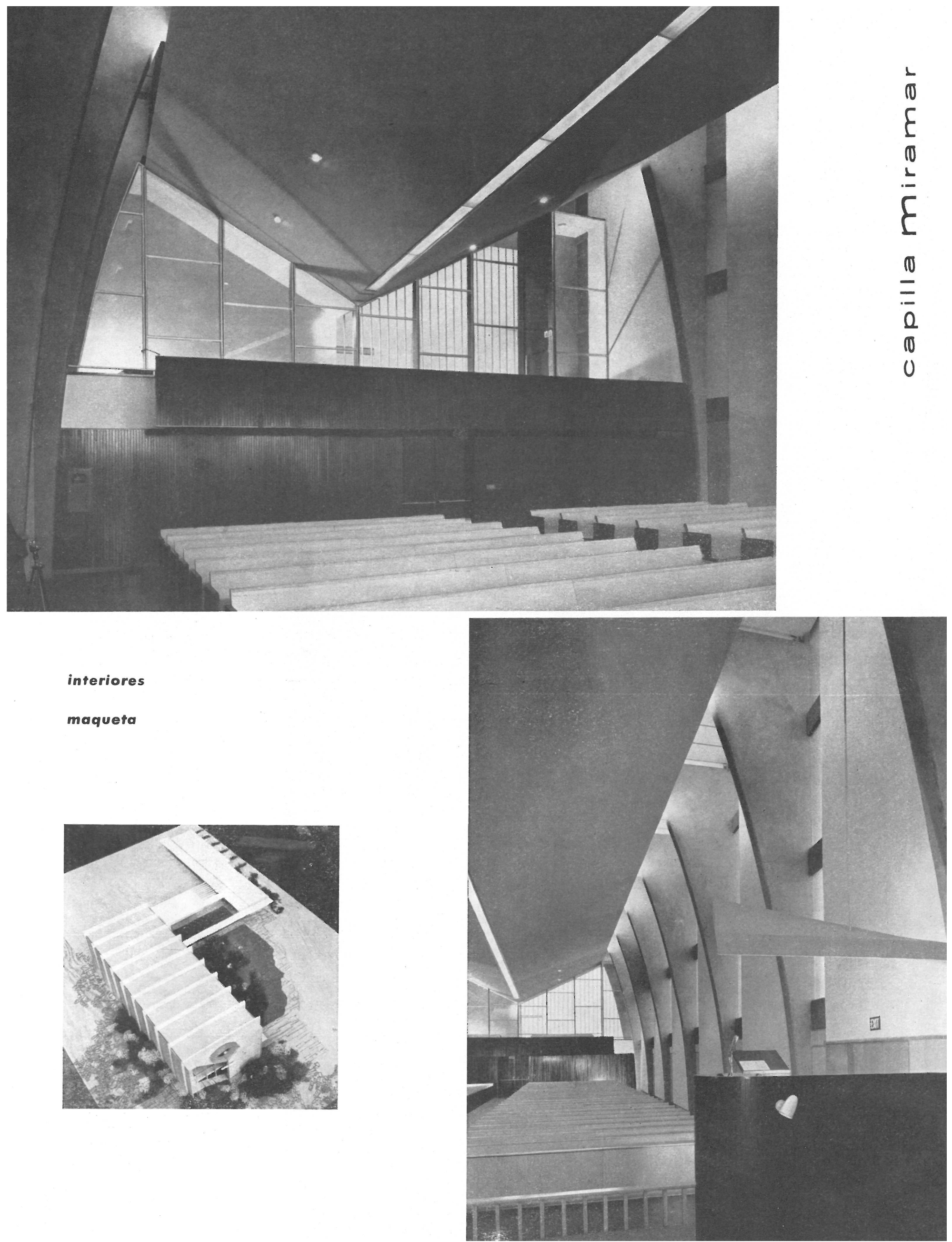




\section{planta}

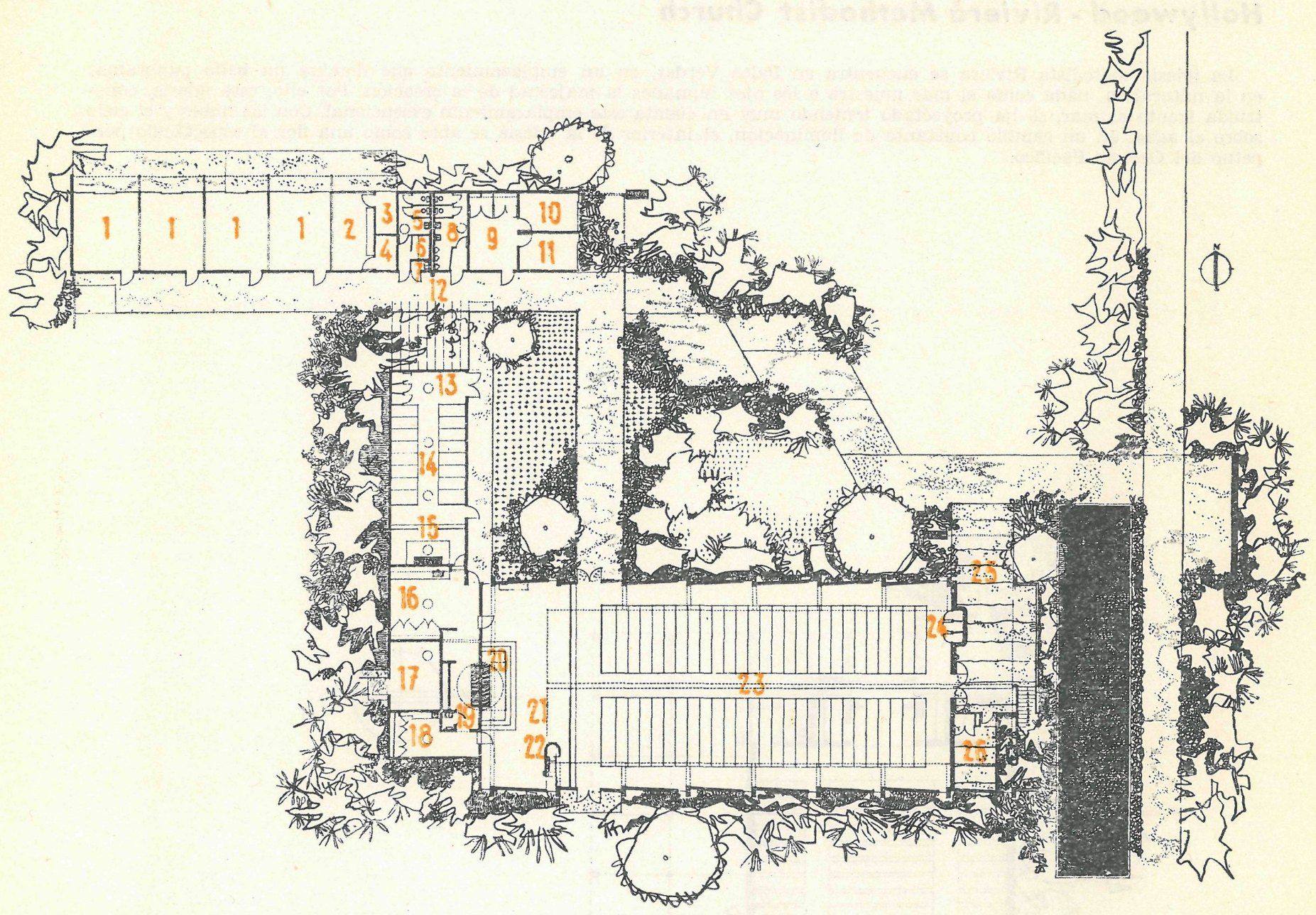

1. Clase.-2. Estrado-escenario.-3. Almacén.-4. Almacén. -5. Mujeres. -6. Descanso.-7. Conserje.-8. Hombres. - 9. Recepción. - 10. Capellán. - 11. Capellán. -

15. Presbiterio.-16. Sacristía.-17. Sala de calderas.12. Fuente.-13. Confesonarios.-14. Capilla matinal. 18. narios.-25. Hall principal.-26. Vestíbulo.

Las salas de vestiduras y sacristía están agrupadas detrás del presbiterio y el altar, con accesos a los servicios, a la capilla principal y la más íntima capilla matutina.

El patio principal de la capilla está formado por: el muro lateral de la misma, al sur; el claustro de la capilla pequeña, al oeste; y el paseo más importante, al este. El acceso en coche a la capilla se hace por el oeste, donde hay una amplia zona de estacionamiento donde los murmullos y ruidos quedan perfectamente separados de la iglesia. Esta zona proporciona además un agradable lugar de recreo de clases dominicales abiertas a la naturaleza y al propio patio principal, con claustro inspirado en el viejo estilo californiano.

La tenue iluminación de la capilla, por la noche, realizada de abajo a arriba, así como la de sus alrededores, está pensada con la idea de que en todo momento brille este foco espiritual de la comunidad y nunca desaparezca en la oscuridad. 


\section{Hollywood - Riviera Methodist Church}

La iglesia metodista Riviera se encuentra en Palos Verdes, en un emplazamiento que domina un bello panorama; en la naturaleza, nada como el mar muestra a los ojos humanos la majestad de la creación. Por ello, esta iglesia, construída frente al mar, se ha proyectado teniendo muy en cuenta este emplazamiento excepcional. Con las nubes y el cielo sobre el agua, en un cambio constante de iluminación, el interior de la iglesia se abre como una flor al espectáculo perpetuo del Océano Pacífico.

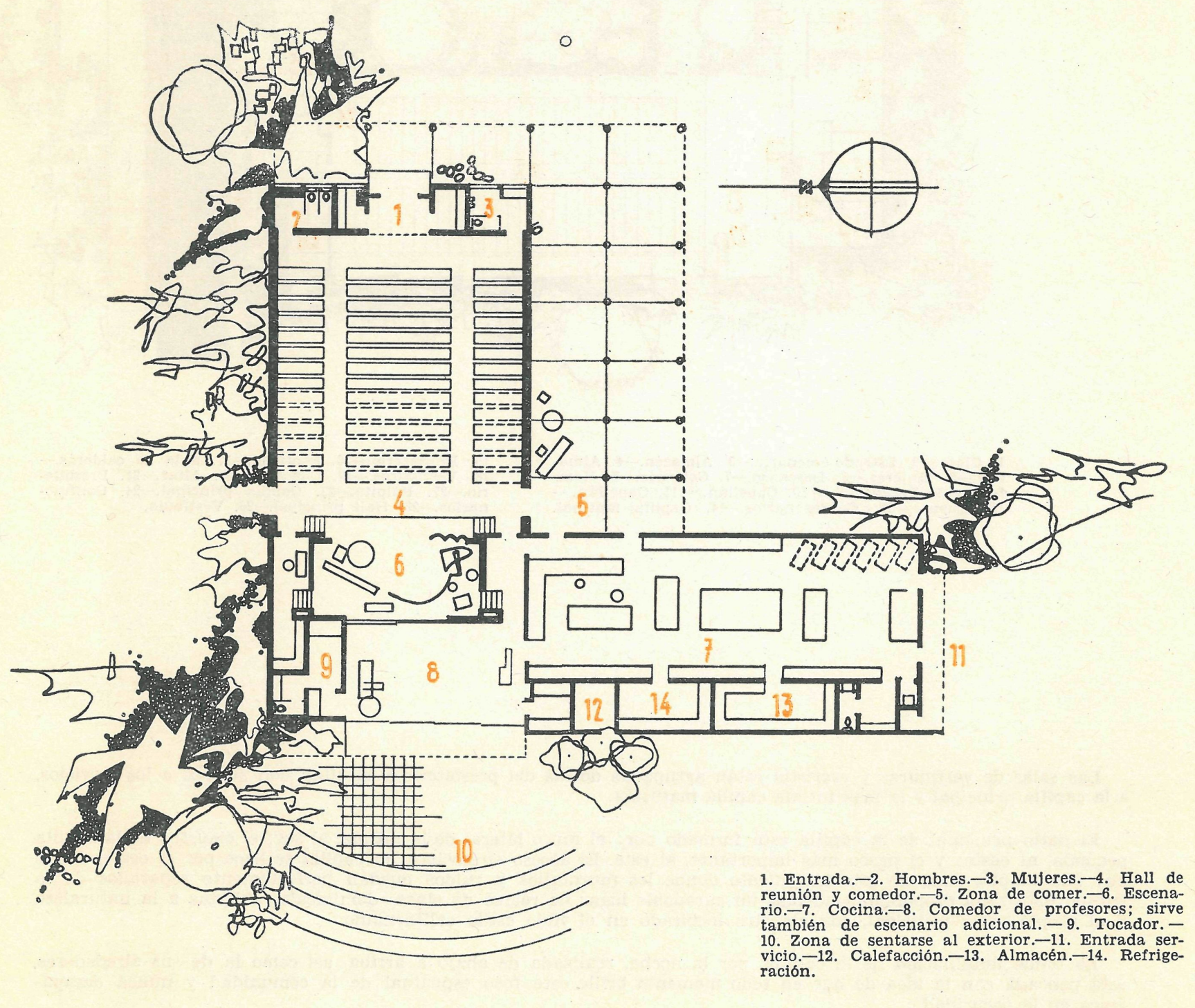

\section{planta}




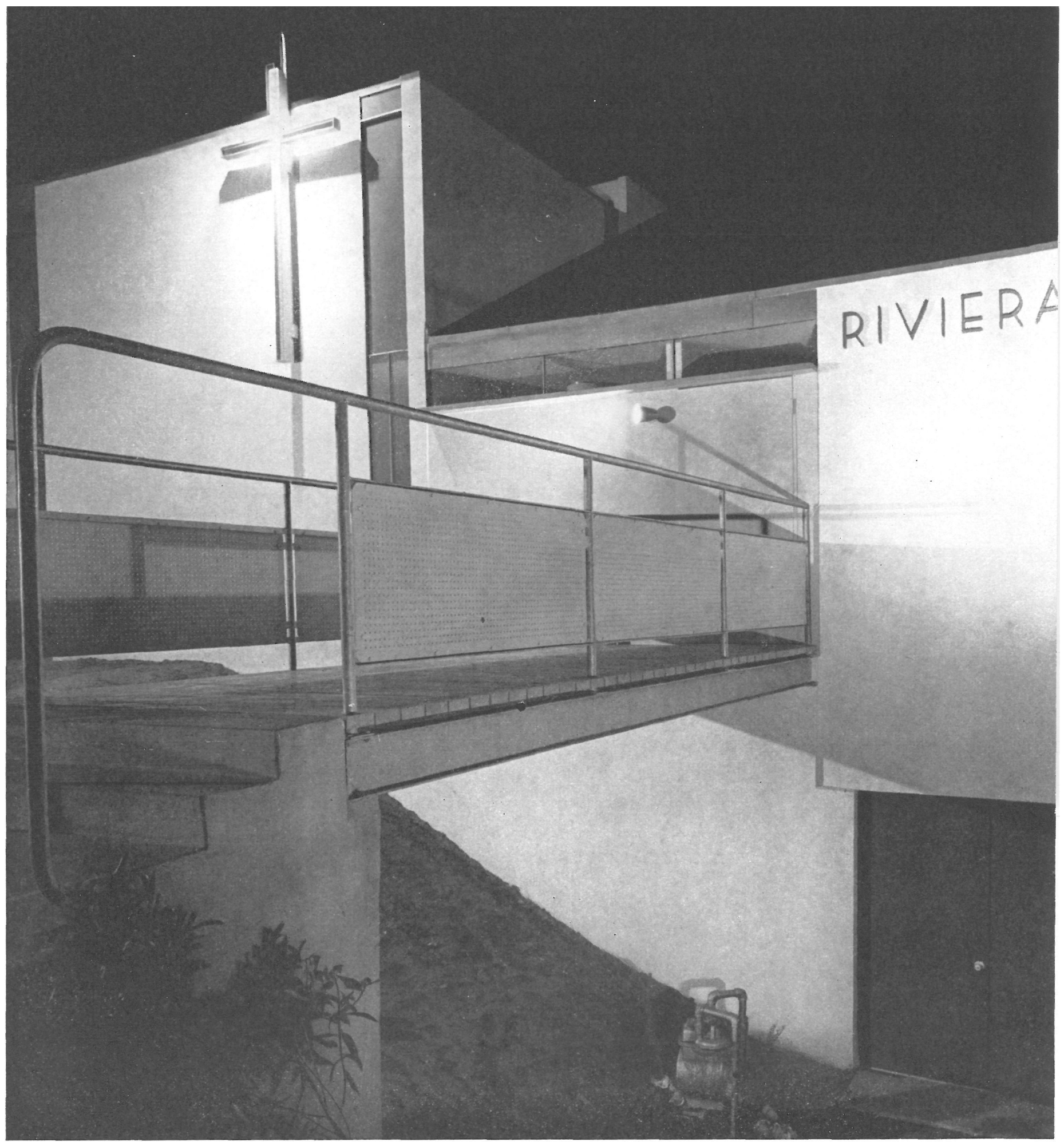

Una terraza ajardinada, cubierta, constituye como un mirador detrás del altar, cuyo cerramiento transparente se abre en los días buenos para buscar el contacto con la naturaleza. Una escalera, reflejada sobre los estanques, conducirá hasta esta terraza protegida por dos de sus lados con altos muros, que se elevan al cielo como manos que se quieren plegar, y que forman una silueta impresionante vistos desde la orilla del mar. Tres miradores, a izquierda y derecha, gozan de bellas vistas sobre el mar, mientras que el coro y el púlpito se distribuyen lo más cerca posible de acuerdo con la Congregación. 

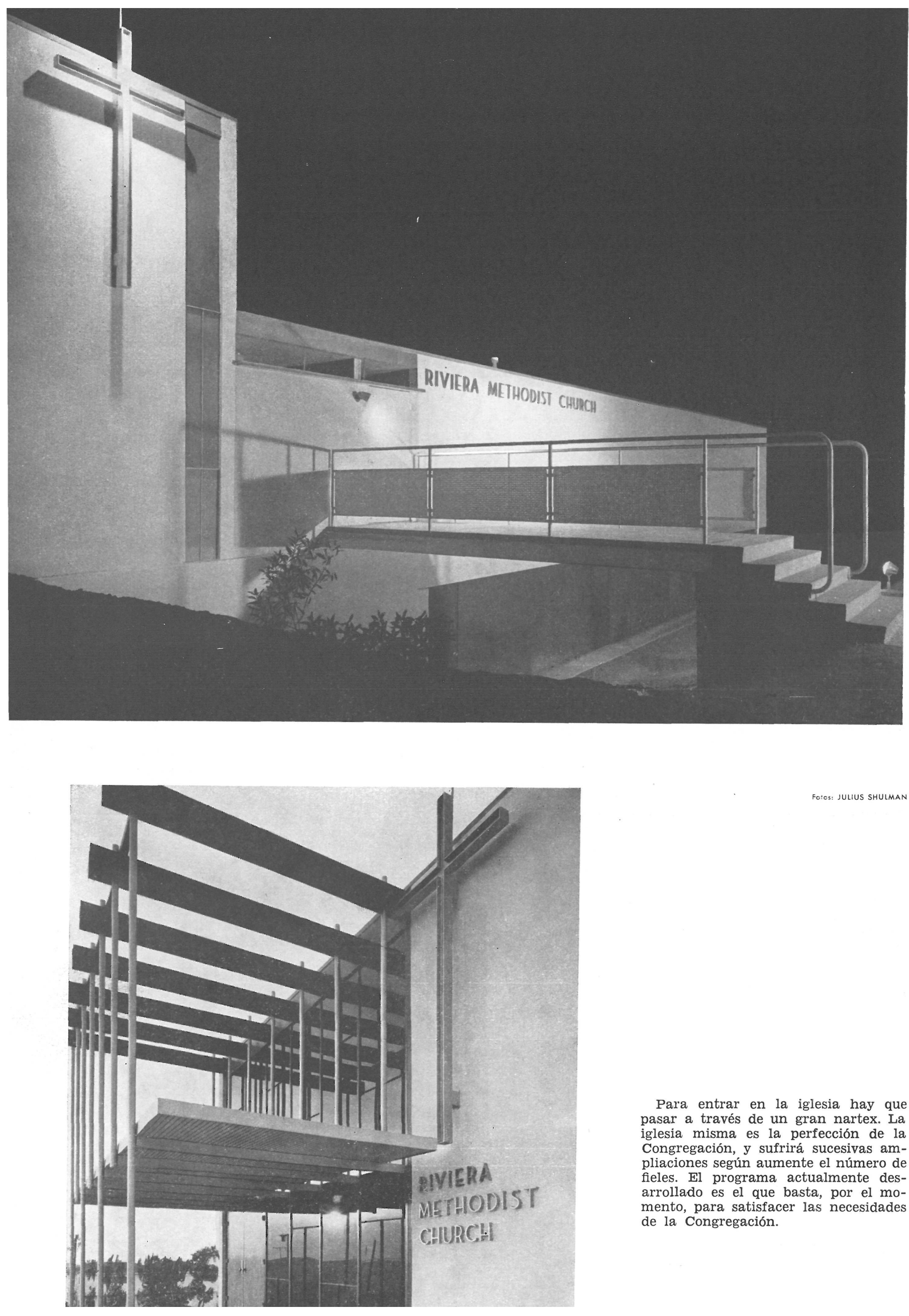

Foios: JULIUS SHULMAN

Para entrar en la iglesia hay que pasar a través de un gran nartex. La iglesia misma es la perfección de la Congregación, y sufrirá sucesivas ampliaciones según aumente el número de fieles. El programa actualmente desarrollado es el que basta, por el momento, para satisfacer las necesidades de la Congregación. 